\title{
Analysis on the Influence of Transportation Infrastructure on Manufacturing Agglomeration in Different Regions
}

\author{
Weimin Dong \\ School of Economics and Management, Beijing Jiaotong University, Beijing 100044, China
}

447851256@qq.com

*Weimin Dong

Keywords: Transportation infrastructure, Manufacturing, Industrial agglomeration.

\begin{abstract}
Industrial restructuring and upgrading has been the focus of national industrial policy, accompanied by industrial migration, the state is also a large-scale construction of transport infrastructure, but specifically, what is the relationship between the two, the use of mainland China 31 Autonomous regions and municipalities in 2008-2015, the regional location entropy as the explanatory variables, respectively, from the theoretical and empirical point of view of rail and highway on the impact of manufacturing agglomeration. The results show that the transport infrastructure has a spillover effect on the manufacturing agglomeration, but the impact of the railway is greater than that of the highway; and the eastern part of the transport infrastructure has greater impact than the other regions.
\end{abstract}

\section{Introduction}

China has been carrying out large scale infrastructure construction, especially in "13th Five-Year Plan" period, China's implementation of major transport infrastructure construction project three-year action plan, to show a perfect wide coverage of the basic network. In the industry, China's industrial structure adjustment, upgrading and some industries from the eastern coastal areas to the central and western regions of the transfer, but from the distribution of traffic networks, China's four major regional traffic lines there are significant differences in the distribution of the eastern and central regions Traffic lines are dense, while the northeast, western transportation network is more sparse, and regional economic and trade and production factors flow, must rely on transportation to achieve. In the traditional theory of location theory, transportation as a location factor is placed in an important position [1]. The allocation of unreasonable, traffic convergence problems will hinder the transfer of industry in the region. Based on this reality, the purpose of this paper is to measure how much the impact of different transport infrastructure on industrial agglomeration, including traffic density and the impact of different types of transport infrastructure on industrial agglomeration.

\section{The current situation of transportation infrastructure construction and manufacturing agglomeration in China}

\subsection{Development of traffic infrastructure}

Since the founding of the country, China's national economic development and population growth led to the growing demand for transportation, after 60 years of construction, China's transport infrastructure construction has achieved remarkable results, Formed by the highway, railways, water transport, civil aviation and pipeline five major modes of transport constitute an integrated transport system. As this study focuses on the impact of transport infrastructure on manufacturing, data is concentrated on railways and highways.

\subsubsection{Railway}

According to the National Bureau of Statistics data show that by the end of 2016 the national railway operating mileage reached $124,000 \mathrm{~km}$, up $2.5 \%$ over the previous year, of which high-speed rail 
business mileage of more than $22,000 \mathrm{~km}$. National railway road network density of $129.2 \mathrm{~km} /$ million square kilometers, an increase of $3.2 \mathrm{~km} /$ million square kilometers.From the data of the four regions, the gap between the operating areas of different railways is obvious. As shown in Fig. 2, the railway mileage of the western region is the highest and the growth rate is the fastest, with an increase of $63.70 \%$ between 2006 and 2015 . The mileage of the northeastern region is relatively slow, from 2006 to 2015 total growth of 0.36 million kilometers, an increase of $26.67 \%$.

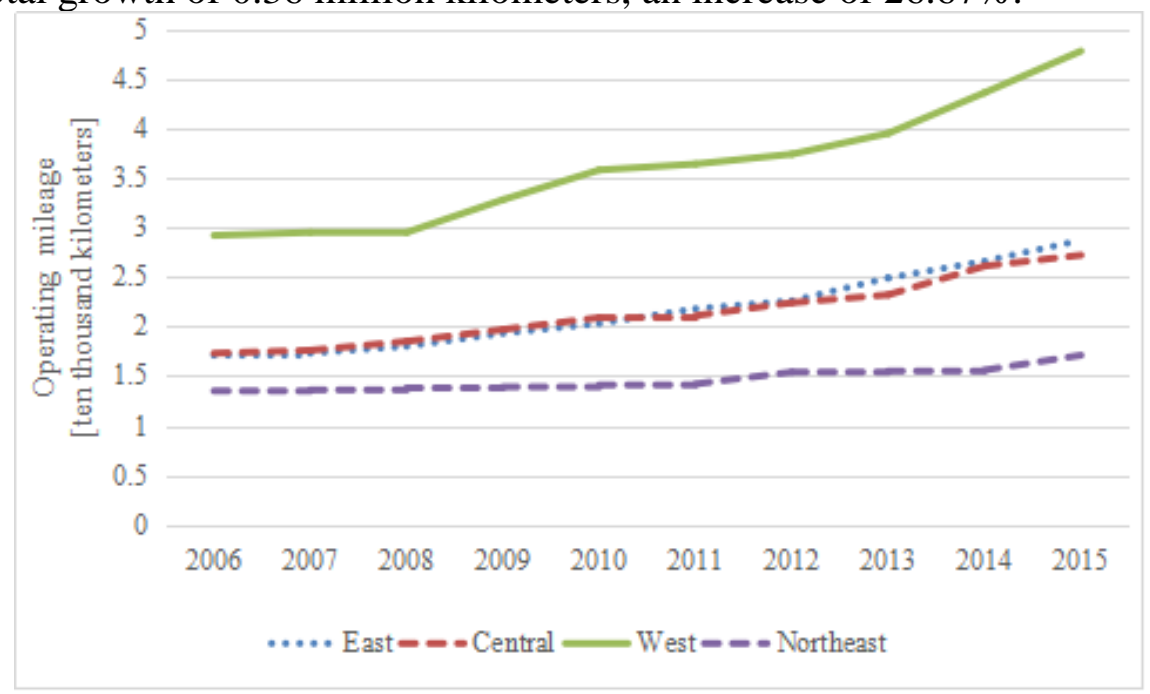

Fig. 1. National railway operating mileage in 2008-2015. ${ }^{1}$

Taking into account the different areas of the land area, so the network density, that is, the mileage per unit area, better reflect the region's transport infrastructure supply situation. In the railway density, the eastern part of the railway network density has always been the leading 2015 railway network density of $0.0313 \mathrm{~km} / \mathrm{km}^{2}$, followed by the central region and the northeast region, the western region and the gap between the larger, the western railway network density most sparse.

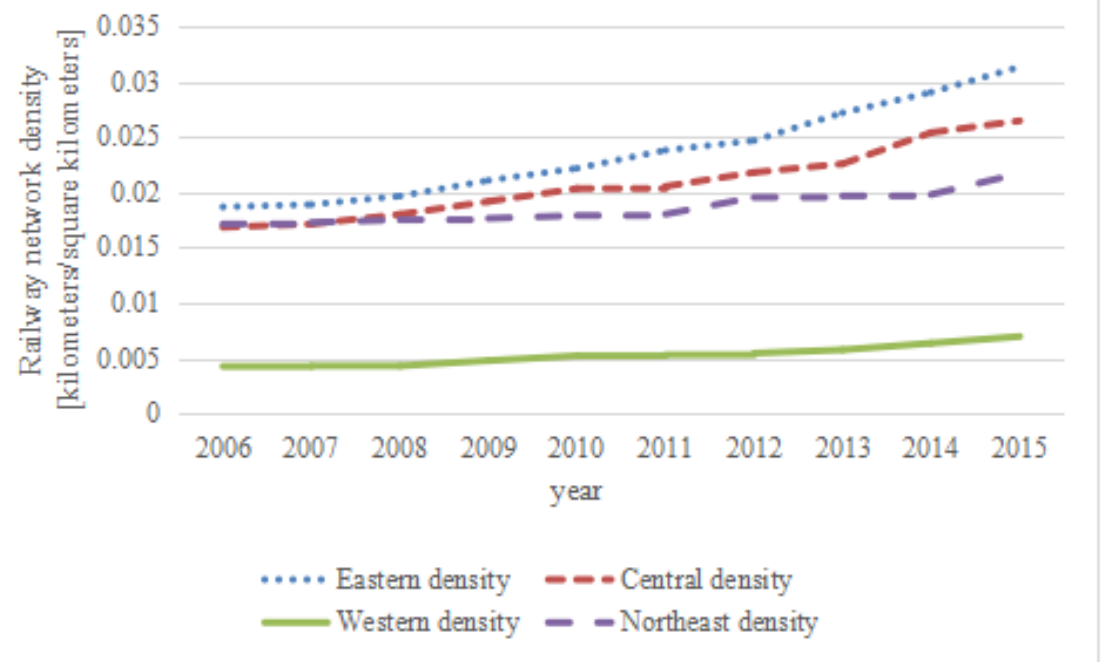

\subsubsection{Highway}

Fig. 2. Railway network density in 2006-2015.

We can see that by the end of 2016 the total mileage of the national highway 469.63 million kilometers from table 1, an increase of $119,000 \mathrm{~km}$ over the previous year. Highway density of 48.92 $\mathrm{km} / 100$ square kilometers, an increase of $1.24 \mathrm{~km} / 100$ square kilometers. While the railway density is much smaller than the highway density. China's traffic infrastructure construction has obvious regional differences, the eastern region and the central region has basically formed a relatively

\footnotetext{
${ }^{1}$ Source: Based on statistical data from the National Bureau of Statistic.
} 
complete transportation network, the western region is still in the transport infrastructure to accelerate the development and construction stage, road network density and transport line quality to be improved.

Table 1. National highway total mileage and highway density in 2011-2016. ${ }^{2}$

\begin{tabular}{ccc}
\hline Year & $\begin{array}{c}\text { Total mileage } \\
\text { [million kilometers] }\end{array}$ & $\begin{array}{c}\text { Highway density } \\
{[\mathrm{km} / 100 \text { square }} \\
\text { kilometers] }\end{array}$ \\
\hline 2011 & 410.64 & 42.77 \\
\hline 2012 & 423.75 & 44.14 \\
\hline 2013 & 435.62 & 45.38 \\
\hline 2014 & 446.39 & 46.50 \\
\hline 2015 & 457.73 & 47.68 \\
\hline
\end{tabular}

\subsection{The present situation of industrial agglomeration in manufacturing industry}

At present, the indicators of industrial agglomeration are: industrial concentration, location entropy, E-G index [2,3]. In view of the impact of different regional transport infrastructure on manufacturing agglomeration, this paper selects the location entropy to represent the degree of industrial agglomeration. The location entropy is also called the regional scale dominance index. When the location entropy is less than 1, it shows that the production level of an industry in the region is lower than the national average and the production is more dispersed. Otherwise, the industry shows agglomeration in the area, Measure industry agglomeration from a regional perspective.

The formula for calculating the location entropy [4]:

$$
L Q_{\mathrm{ij}}=\frac{X_{i j} / \sum_{i} X_{i j}}{\sum_{\mathrm{j}} X_{i j} / \sum_{i} \sum_{\mathrm{j}} X_{i j}} .
$$

In formula (1), $X_{\mathrm{ij}}$ is the number of practitioners representing the $\mathrm{i}$ th industry in the $\mathrm{j}$ th region; $\sum_{i} X_{\mathrm{ij}}$ is the number of employees in the whole society; $\sum_{\mathrm{j}} X_{\mathrm{ij}}$ is the number of practitioners $\mathrm{i}$ industry in the country; $\sum_{i} \sum_{\mathrm{j}} X_{\mathrm{ij}}$ is the number of employees in the country.

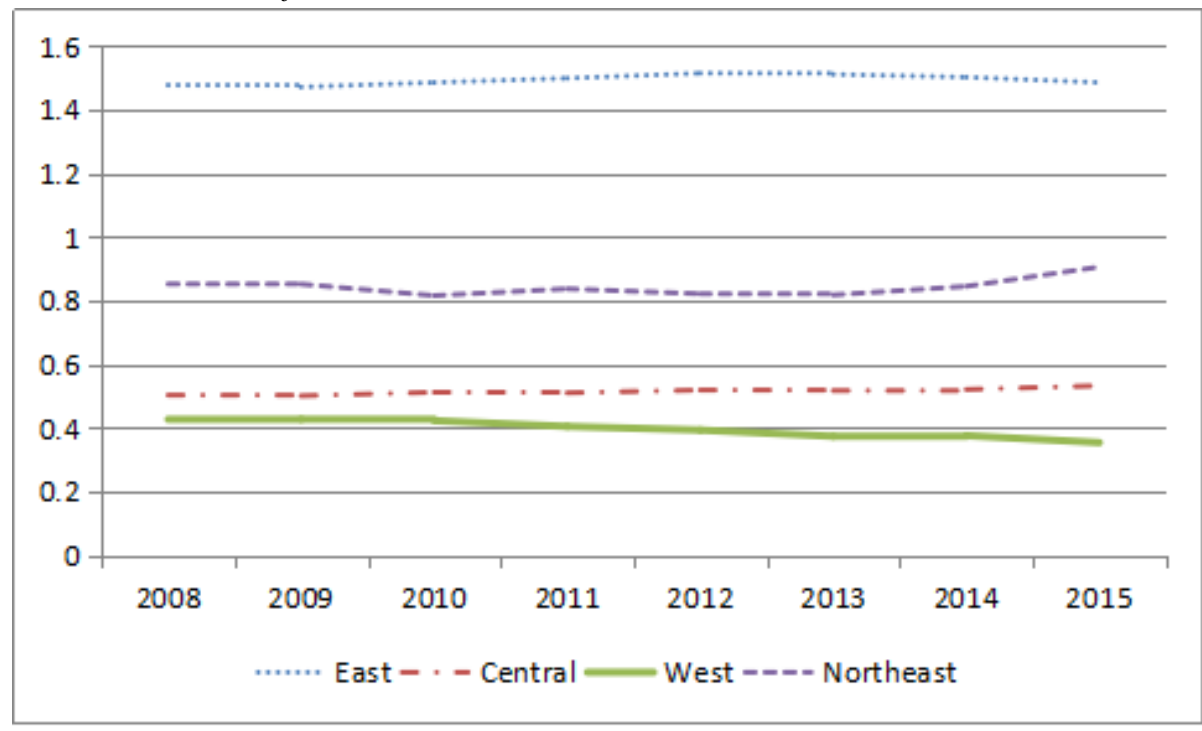

Fig. 3. Four regional manufacturing industry location entropy in 2008-2015.

In the case of the regional entropy of the industrial agglomeration level in China, the calculated data are derived from the statistical data of the national statistical offices. Based on the statistical data

\footnotetext{
${ }^{2}$ Source: transport industry development statistic bulletin in 2016.
} 
of 31 provinces and municipalities in mainland China, the average location entropy of the four major economic regions in 2008-2015 is calculated.

The location entropy of the manufacturing area in the eastern region is much larger than that in other regions(Fig.3.). The entropy of the eastern and western regions shows a downward trend, and the northeast region is characterized by rising entropy. The concentration of manufacturing in the eastern region is higher than the national average level, the industrial agglomeration is obvious, with a certain scale advantage, the central and western regions of the manufacturing concentration is far below the national average. In general, the present situation of manufacturing agglomeration in the eastern, central, western and northwest regions of China is similar to that of China's railway and highway networks, that is, the spatial distribution of transport infrastructure and manufacturing cluster is consistent, but the central area And the high density of the railway network, but the degree of industrial agglomeration is not high.

\section{Theoretical analysis}

Industrial agglomeration refers to the same type or different types of related industries within a certain geographical concentration, aggregation. Geography combines transaction cost mechanisms and learning innovation as a key mechanism for industrial agglomeration [4]. Recent studies have shown that industrial agglomeration is the result of economies of scale and the reduction in transport costs and the flow of factors.

\subsection{The impact of traffic infrastructure on industrial agglomeration}

The transportation infrastructure is mainly through the impact of transportation costs and the flow of factors of production on the industrial agglomeration spillover effect. The transport infrastructure not only improves transport speed, shortens transit times, but also increases transport stability and reduces transportation costs [5]. Krugman (1991) proposed a central-periphery model to explain industrial agglomeration, which he believed could be transported at zero cost between any region, while the transportation cost of manufacturing products followed the "iceberg cost hypothesis" [6]. As a result, when transport costs are low, manufacturing will focus on the same area and become an economic center, so transport infrastructure will drive industrial agglomeration by reducing transportation costs.

On the other hand, the perfect transportation network has a significant effect on the flow of factors of production, by shortening the transportation time and transportation costs to enable enterprises to gather in the traffic infrastructure is relatively complete area. The gathering of productive service industries promotes local labor productivity [7].

\subsection{The impact of other factors on industrial agglomeration}

\subsubsection{R\&D Input}

In the neoclassical economy, labor market sharing, intermediate product input and technology spillovers are three factors that affect industrial agglomeration. And corporate R\&D investment in a strong region or industry will attract a large number of high-tech talent gathering, while the higher $\mathrm{R} \& \mathrm{D}$ investment also means that the enterprise technology spillovers strong.

\subsubsection{Market Scale}

The new trade theory that enterprises will gather in the market accessibility of the better region, that is, the larger the market size, the higher the degree of industrial agglomeration. Industry scale regions are more likely to attract enterprises to enter, business gathering to bring more labor demand and market demand, so as to attract the gathering of related industries, the greater the economies of scale, the regional industrial agglomeration level is also higher.

\subsubsection{Local Government Forces}

Local government facilities into the barriers, is not conducive to the flow of industrial production factors. China as a developing country, although it has always stressed that the market forces as the 
main regulatory mechanism, but the process of China's industrial development in the role of the government cannot be ignored, local governments at all levels of local protectionism is easy to trade barriers, become one of the factors hindering industrial agglomeration.

\section{Empirical analysis}

\subsection{Variables and data}

Using the location entropy LQ as the explanatory variables to examine the regional level of industrial agglomeration. In the interpretation of variable settings, because of China's manufacturing industry on the road and rail two kinds of transport the use of the widest range, so take the four major regions of the corresponding years of railway and road density that the regional transport infrastructure construction, and the second entry The model is used to reflect the nonlinear relationship between transport infrastructure and industrial agglomeration.

The market size variable is represented by the average output value of the secondary industry enterprises in the region, that is, the ratio of the total output value of the secondary industry to the number of enterprises. (R\&D) input intensity, that is, the ratio of R\&D inputs to GDP in the region. Local government forces to take the regional output value of state-owned enterprises accounted for the proportion of industrial output value of the representative, of which the proportion of state-owned enterprises accounted for the greater the government protection efforts.

The data interval is from 2008 to 2015, the data from the National Bureau of Statistics, "China Statistical Yearbook" and "China Industrial Statistics Yearbook".

\subsection{Measurement model}

$$
L Q=\beta_{0}+\beta_{1} T L+\beta_{2} G L+\beta_{3} G M+\beta_{4} R D+\beta_{5} G O V .
$$

Where TL represents the railway density $\left(\mathrm{km} / \mathrm{km}^{2}\right)$ in region i, and GL represents the road density $(\mathrm{km} / \mathrm{km} \mathrm{km})$ in region $\mathrm{i}$; GM is the market scale, and the regional secondary industry average The output value (billion yuan / month); RD represents the intensity of investment in R\&D of the region $\mathrm{i}$ in year $t$; The ratio of the value of state-owned enterprises to GDP in the region represents GOV.

\subsection{The result of regression}

Data from the four regions of the eastern, central, western and northwest regions are estimated separately. According to the Hausman Test, the model is used to determine the model using the fixed least square method. The results are as follows:

Table 2. Regression results of four regions.

\begin{tabular}{cccccc}
\hline $\begin{array}{c}\text { Explanatory } \\
\text { variables }\end{array}$ & total & east & central & west & Northeast \\
\hline C & $1.2691^{* * *}$ & $0.7417^{* *}$ & $-0.1263^{*}$ & $0.1352^{* *}$ & $0.9197^{*}$ \\
\hline TL & $16.1066^{*}$ & $16.574^{* *}$ & $3.5420^{* *}$ & $6.7566^{*}$ & $2.5842^{* *}$ \\
\hline GL & $1.0593^{*}$ & $0.9432^{* *}$ & $0.5131^{*}$ & - & $0.3779^{*}$ \\
\hline GM & 0.0422 & $0.0923^{*}$ & $-0.0995^{*}$ & -0.0574 & 0.0977 \\
\hline RD & 0.000 & - & $-0.0006^{*}$ & - & $-0.0009^{*}$ \\
\hline GOV & $-0.0351^{*}$ & $0.0613^{* *}$ & $0.3149^{*}$ & $0.6197^{*}$ & $-0.2547^{*}$ \\
\hline $\mathrm{R}^{\wedge}$ & 0.9249 & 0.9862 & 0.9711 & 0.9623 & 0.7182 \\
\hline
\end{tabular}

Note: $* * *$ indicates significant at $1 \%$ level, $* *$ indicates significant at $5 \%$ level; * indicates significant at $1 \%$ level. The sign "-" indicates a new regression result in the regression process because it is not significant and removes no significant variables.

The results show that: 1) In general, the traffic infrastructure has a spillover effect on the agglomeration of the manufacturing industry, which indicates that the railway and the road have a certain influence on the manufacturing agglomeration. However, the railway density and the manufacturing industry are significant Large positive relationship, while the road density on the manufacturing cluster of the smaller coefficient of influence. 2) From the regression results of the 
four regions, the railway density has a greater effect on the agglomeration of the eastern region than in the other three regions, which indicates that the railway density in the eastern region has a greater effect on the development of the eastern region, Especially in the eastern region itself is more perfect railway construction, high quality railway network density and high transport efficiency is the direction of manufacturing agglomeration. However, the spillover effect of the highway on the industrial agglomeration in the western region is not significant, which may be related to the natural conditions in the western region. The manufacturing industry is generally concentrated in the railway density. 3) Control variable analysis. Market size, the proportion of state-owned enterprises and R\&D investment accounted for the role of the manufacturing sector in the regional level of data there is a big difference. The size of the industry and the proportion of state-owned enterprises accounted for the data is small and not significant, indicating that the role of the two manufacturing clusters smaller.

\section{Summary}

Based on the regional data of 31 provinces and municipalities in China in 2008-2015, this paper uses the regional location entropy as the explanatory variables to analyze the impact of railways and highways on manufacturing agglomeration from the theoretical and empirical perspectives. The results show that the traffic manufacturing industry does have a significant spillover effect on the manufacturing agglomeration. However, the spillover effect of the railway to the manufacturing agglomeration is greater than that of the railway. From the regional level, the railway and highway to the eastern region The role of industrial agglomeration is greater than that of middle, west and northeastern regions, but the agglomeration effect of highway on the western region is not significant. In this paper, there are many shortcomings, such as because the data time span is small, may lead to regression results appear deviation; There are fewer control variables to consider, and other important variables may be omitted.

\section{Acknowledgement}

First of all, the most sincere thanks to a national statistics from my staff, their hard work for us to create a convenient and detailed data, let me to obtain the data of this paper support; Secondly, I would like to thank my mentor, for his detailed answers and help to the confusion in my thesis. Finally, thanks to my parents for their encouragement when I was in trouble.

\section{References}

[1] Chengjin Wang and Fengjun Jin, Research Progress and Prospect of China's Transportation Geography, Advances in Geography, vol.6, pp. 66-78, 2005.

[2] He Liu and Jian Wang, Space Effect of Transportation Infrastructure on Manufacturing Agglomeration: An Empirical Analysis Based on Region and Industry, Southeast China Academic, vol.4, pp. 96-105, 2014.

[3] Chen Ling, Yi Zheng and Jun Li, Study on Driving Factors of Industrial Agglomeration in China, Systems Engineering, vol.8, pp. 99-105, 2013.

[4] Taotao Deng, Dandan Wang and Dan Wu, Traffic Infrastructure, Spatial Spillover and Geographical Agglomeration of Manufacturing Industry--Based on Provincial Panel Data Analysis, Regional Economic Review, vol.2, pp. 33-40, 2017.

[5] Changhong Miao, Yahua Wei and Lachang Lu, New Economic Geography, Beijing Science Press, pp. 189-195, 2012. 
[6] Krugman P, Increasing returns and Economic Geography, Journal of Political Economy, vol.99, pp. 483-499, 1991.

[7] Wei Hui and Xianfeng Han, Commercial services industry agglomeration promotes regional labor productivity, Quantitative Economics and Economic Research, vol.10, pp. 37-56, 2016. 